THE POLICY OR FUNCTION OF THE LAW OF BILLS AND NOTES

\title{
PART II *
}

\section{JoHn S. Strahorn, JR. i \\ IV. The More Desirable Commercial Conduct Creating the Substantive Advantages}

Now we deal with the facts which create the status of the holder in due course. These extrinsic or background facts, when incidental to an approved transfer of the instrument to a holder, give the transferee the status of a holder in due course with the more attractive substantive advantages of such a status. The tenor of these extrinsic facts is that the transaction be one of the highest commercial morality, one so far superior to the ordinary run of bills and notes transactions as to be entitled to a relatively greater reward.

This reward of substantive advantages is held out primarily to encourage the happening of these extrinsic facts which serve to make the transaction of the highest commercial order. But, incidentally, these rewards have, as do the lesser procedural advantages, the further purposes of encouraging the occurrence of transactions which otherwise might not be entered into at all and of fostering execution of transactions, which might otherwise take place informally, in the formal manner of bills and notes. Thus it is that the determination of what are the operative facts leading to the substantive advantages cannot always be made solely on the basis of what is the highest type commercial conduct but, occasionally, must be determined on a basis of fostering the happening of formal type transactions. Thus we shall see that both the rule that an antecedent debt is value and the rule that one may be a holder in due course even when he takes under suspicious circumstances not amounting to bad faith effect a compromise between the policy of fostering the highest type of commercial transaction and that of encouraging the circulation of negotiable paper generally.

A point which cannot be emphasized too strongly is that it is not necessary in all cases to determine whether the holder is a holder in due course. Only when there is a personal defense to liability or a claim of

*The first installment of this article, containing footnotes $I$ to 227 , appeared in the April issue of the REviEw. (I939) 87 U. Of PA. L. REv. 662.

$\dagger$ A. B., I922, St. John's College; LL. B., I925, Washington and Lee University; S. J.D., 1926, Harvard University; J. S. D., I93I, Yale University; Professor of Law at University of Maryland School of Law; author of The Effect of Impossibility on Criminal Attempts (1930) 78 U. of PA. L. REv. 962 ; Criminology and the Law of Guilt (I936) 84 U. OF PA. L. REv. 491, 600;A Reconsideration of the Hearsay Rule and Admissions (I937) 85 U. of PA. L. REv. 484, 564, and other articles in legal periodicals. 
ownership of the instrument does it become necessary to solve the problem of the status of the holder under the operative facts presently to be discussed. If there is neither personal defense nor claim of ownership, the holder will prevail simply as an ordinary holder. If there is a real defense or claim, he will lose, even though he be a holder in due course.

As we have seen, the substantive advantages are held out in pursuance of a vague principle found sporadically throughout the law that the bona fide purchaser who has changed his position in reliance on the apparent situation wherein the obligor or owner has made the loss possible should be protected. Thus it is that, the equities being equal, the loss is thrown on the one who made it possible. Thus the two legalistic elements of the operative facts making for a holding in due course would be change of position and ignorance of the defect in the transaction. When these are combined with the law merchant policy of fostering commercial transactions of both high and low morality we get the three basic elements of a holding in due course, i. e., value, good faith and absence of notice, and purchase before maturity.

To be a holder in due course one must already be an ordinary holder. ${ }^{228}$ If a necessary signature be lacking or be forged, or if the instrument does not measure up in form to the slighter standard required in order that the procedural advantages be used in enforcing it, then the person in possession is not even an ordinary holder and cannot aspire to be a holder in due course.

The problem arises chiefly in determining whether the payee can be a holder in due course and has largely been settled in favor of such a possibility. The status of the holder in this connection is rarely in issue as it is infrequent that there exists a personal defense or claim of ownership of which the payee is ignorant or with which he lacks connection in such a manner as to make good faith on his part possible. But to the extent to which it can be a problem-principally in the situation involving breach of some collateral agreement between the principal debtor and his surety on the instrument-it is commercially desirable to extend to the payee the substantive advantages, for in this way payees will be encouraged to perform the commercially desirable conduct of lending money on the faith of promissory notes.

\section{A. Purchase for Value}

As we have seen, the principal purpose of the whole law of bills and notes is to foster the exchange of money and the sale of goods by

228. Contrast the position of one holding under NEgotiable INSTRUMENTS LAW, $\S 49$. In the ensuing footnotes the various sections of the Uniform Negotiable Instruments Law will be referred to merely by section number. 
providing substitutes for money and instruments of credit. This policy is seen to have unusual emphasis in its application to the instant topic of the value ${ }^{229}$ furnished by the holder at the time of his taking which, other things being equal, makes him a holder in due course; for to be a holder in due course, the holder must, among other things, have sometime transferred some money or furnished some goods, services, or other consideration on the credit of the instrument which he has taken. ${ }^{230}$

But it is not necessary that the one taking the instrument allegedly as holder in due course shall actually advance the money or sell the goods on credit at the time of his taking. The rule that the taking of an instrument in satisfaction of an antecedent debt constitutes the taker a holder for value ${ }^{231}$ is a recognition of the commercial desirability of the further extension of credit in a transaction where the money has once been lent or goods sold or services rendered on credit. Despite the fact that no new value is surrendered, a further credit transaction is actually entered into when a negotiable instrument is taken for an antecedent debt, and the law's policy of encouraging credit transactions carried out.

The rule that an antecedent debt is value represents a compromise of several considerations involving commercial expediency. Were the emphasis entirely on fostering only the highest type of commercial transaction, the rule might well be that the advancement of new value is necessary. So it would be if the emphasis were entirely on "change of position". It is probable that, in most cases, he who has taken for an antecedent debt has not changed his position, i. e., could as well pursue his remedy on the antecedent debt were he denied recovery on the instrument as a holder in due course. ${ }^{232}$ To be sure, there might be some instances where, because of reliance on the instrument, the creditor has postponed collection of the debt and thereby let slip an opportunity which once existed to avail himself of assets of the debtor now squandered. But because it would be impracticable to pursue a subjective investigation in every case into whether the holder had changed his position on the antecedent debt, the rule of the case law and the Statute takes the position that, as he might have so changed his position and thus performed the commercially desirable act of transferring negotiable paper, the transferee for an antecedent debt should be considered a holder for value.

229. $\$ \S 52(3), 191$.

230. $C f . \$ \S 6(2), 24$.

23I. $\$ 25$.

232. Of course, from the technical standpoint, there is a "detriment" in that the bringing of an action on the claim has been postponed. 
Further, in order to encourage the commercially desirable use of negotiable instruments as collateral security for loans, the Statute recognizes ${ }^{233}$ that one who holds by way of pledge may be a holder for value, even where the pledge is for an antecedent debt, although, to be sure, only to the extent of the amount of his lien. While the pledge of an instrument is, perhaps, a less desirable transaction than its sale outright, yet by the pledge the ultimate purpose of the law of bills and notes to foster the extension of credit has been served and, to the extent necessary to protect the one who has extended the credit, i. e., to the extent of his lien, he is given the status of holder in due course.

While the Statute, by virtue of its rule that value includes any consideration sufficient to support a simple contract, ${ }^{234}$ apparently recognizes a promise or other executory matter as value, it qualifies this rule by a further provision ${ }^{235}$ that a transferee who receives notice of any defect before he has given all of the agreed value is a holder in due course only to the extent of that which he had previously performed. This, too, serves the basic purpose of the law of bills and notes by encouraging those who have promised the exchange of money or the sale of goods on credit to hasten the performance of such promises, on penalty of receiving notice of defects before they are performed. Until the promise is performed there is no exchange of money or extension of credit and if such exchange or extension should occur after notice received, the promise has not then been performed under the highly desirable circumstances which must surround the transaction in order that it be entitled to the substantive advantages of a holding in due course.

This doctrine of pro tanto holding in due course where executory value is not fully performed before notice is received is involved in two typical commercial situations where holding in due course is at stake. The first is that of the transfer of a negotiable instrument to a holder who gives as value his own negotiable instrument and then receives notice of the defect in the instrument he has taken in time to stop or refuse the payment of the instrument he has given. The second is that of the transfer of the instrument to a bank in exchange for deposit credit, where the bank receives notice of the defect in time to debit the account of the depositor for the sum credited in exchange for the instrument. The courts seem to have reached diametrically opposite results on these problems, although, as a matter of strict legal logic, both involve executory value not fully performed at the time notice has been

233. § 27.

234. $\S 25$.

235. §54. 
received. Then, too, as a matter of commercial expediency, the problems are similar.

In the case of negotiable paper as itself value for the transfer of other negotiable paper (where the holder must hold in due course in order to recover) the conclusion seems to be that negotiable paper is to be treated as executed value from the start and that the taker of the defective paper is not required to attempt to stop payment or to refuse payment on his own paper, as the case may be. There is not even required a showing that such taker is himself liable to a holder in due course of his paper. The difficulty and embarrassment of stopping or refusing payment, even as to an ordinary holder, and the possibility that the paper has gotten or will get to a holder in due course, militate in favor of the commercially desirable rule that negotiable paper given for other paper is itself executed value, the performance of which need not be suspended merely because of the receipt of notice of the defect in the instrument taken. In view of the numerous rules treating negotiable instruments differently from common-law contracts, it would, indeed, be paradoxical for the law of bills and notes to consider the giving of one of its own instruments as nothing more than an unperformed simple promise. To treat both parties to an exchange of negotiable instruments as holders for value does tend to foster the free circulation of such paper.

On the other hand, in the deposit credit situation, the rule seems to be to the contrary and the courts have treated the promising of the honoring of checks against a bank account as an executory simple promise, which must be performed before notice is received. They require either that the specific item must have been checked out, by the "first in, first out" rule, or, more strictly, that the intervening balance must have gone below the amount of the defective item before the bank will be considered (even pro tanto) a holder for value. It would seem that the other rule that the bank is a holder for value as soon as it has granted unconditional deposit credit, i. e., has promised to honor checks against the item, more closely accords with commercial desirability and is, in addition, analogous to the rule for commercial paper. Business expediency seems to demand that a bank be not required to debit a customer's account, thereby running the risk of turning down his checks and embarrassing both him and the bank, just because some vague fact which a court might construe as notice comes within its purview. If the maker, drawer, acceptor, or indorser of negotiable paper is not required to stop or refuse payment when he could, why should a bank be required to "stop payment" on its customers' checks by debiting an item of deposit credit? It would seem that commercial expediency 
should indicate that both the giving of negotiable paper and the granting of unconditional deposit credit should be treated as executed value.

\section{B. Purchase in Good Faith and Without Notice}

This category of the operative facts of holding in due course includes the residual bulk of the problems of the more desirable commercial conduct which is entitled to the higher rewards of the substantive advantages of holding in due course. Where the preceding topic was concerned with the unitary problem of the value invested by the one claiming as a holder in due course, and where the following one will deal with the requirement that the investment be in a future obligation, the current topic serves as a "catch-all" for the subsidiary points dealing with the "commercial morality" aspect of the transaction set up as entitling the one concerned to the higher status of the substantive advantages.

And yet, while the law is here concerned with the intrinsic honesty of the transaction by which the alleged holder in due course took, it has deliberately refrained from requiring of the taker, in order that he be such a holder, too high a standard of conduct. Holding in due course will not be defeated if the holder took under suspicious circumstances giving "constructive notice", unless these circumstances are sufficient either to give the taker "actual knowledge" or to make his taking one in "bad faith". 236 This rule must be rationalized as a compromise between the desire to promote commercial transactions of the utmost honesty and the desire to have the transactions take place in the first instance. Setting the test too high (by allowing suspicious circumstances to defeat holding in due course, rather than be merely evidence of bad faith) might tend to discourage persons from dealing in negotiable paper. So it is that persons expecting to secure the substantive advantages run only the risk of having their bad faith in the matter shown, rather than that of there being constructive notice through suspicious circumstances. The analogy is to the law of sales, which tolerates a certain amount of "puffing" of his wares on the part of the seller, without his incurring liability for warranty of quality.

The specific rules which are concerned with this element of the operative facts of holding in due course fall into two classes, in that they are concerned respectively with facts coming to the knowledge of the holder from the appearance of the instrument and facts coming to his knowledge extrinsically. The emphasis is, of course, on facts coming to the knowledge of the holder at the time of taking, for whether the problem be one of "actual knowledge" or "bad faith", both are

$236 . \$ 552(3), 52(4), 56$. 
concerned with the significance of facts occurring within the knowledge of the holder before and at the time of taking.

In the first group, dealing with facts coming to the knowledge of the taker from the four corners of the instrument, there is, first, the statutory rule ${ }^{237}$ that the instrument must be complete and regular on its face at the time of taking. Another section ${ }^{238}$ makes immaterial, however, the lack of a date. A mere statement of the transaction giving rise to the instrument ${ }^{238}$ neither defeats negotiability nor serves to put the taker on notice that the named consideration had not been performed. Of course, the fact that a signature is appended "per proc" serves to put the taker on notice of limited authority ${ }^{240}$ and a conditional indorsement acts similarly with reference to the non-performance of the condition. ${ }^{241}$ The restrictive indorsement serves at least to put the taker on notice of the interest sought to be protected by the restriction and, certainly as respects the "pay only" and "agency" types, completely precludes a subsequent holding in due course. Whether the "trustee" type restrictive indorsement also accomplishes this latter destructive effect has been the subject of some dispute under the conflicting sections of the Statute. ${ }^{242}$

The question of what facts extrinsic to the four corners of the instrument will defeat a holding in due course from the standpoint of good faith and want of notice is a more flexible one and one calling into play the "actual knowledge" and "bad faith" tests the Statute has set up with respect to the taker's awareness of an "infirmity in the instrument or defect in the title of the person negotiating it". 243 The Statute itself ${ }^{244}$ recognizes awareness of the obligor's prior refusal as the equivalent of an awareness of the infirmity or defect in the rule that the taker must have taken without knowledge of prior dishonor.

Many typical situations have given rise to difficulty under this element of good faith and want of notice. Such include the potential equity problem where it is plausible that, from the knowledge of the negotiator's use of the value received, the taker should be aware of his abuse of a trust; the problem of whether knowledge of overdue interest or instalments is equivalent to knowledge of prior dishonor; and the question of whether the instrument's being in the possession of one

237. $\$ 52(I)$.

238. $\$ 6(\mathrm{I})$.

239. $\$ 3(2)$.

240. §2I.

24I. §39.

242. $\$ \$ 36,37,47$. See Smith, The Concept of "Negotiability" as Used in Section 47 of the Negotiable Instruments Law (1929) 7 TEx. L. REv. 520.

243. $\$ 52(4), 56$.

244. \$ 52 (2). 
apparently not in chain of title is sufficient to preclude a holding in due course.

\section{Purchase Before Maturity}

Last of the three major elements of holding in due course is that of purchase before maturity. The basic theory is that only a transfer of not yet overdue paper is sufficiently desirable to deserve the substantive advantages. ${ }^{245}$ The question, of course, arises as to when the paper is so overdue as to preclude its being subsequently taken in due course. In the case of time paper, this is determined by the due date shown on the face of the instrument. ${ }^{246}$ Demand paper, on the other hand, presents a greater problem. Such paper becomes overdue when negotiated "an unreasonable length of time after its issue" ${ }^{247}$ - whatever this means. As to persons whose liability accrues on the instrument after maturity, it is regarded as demand paper. ${ }^{248}$

Particularly important is the question of the status of one who acquires order paper before maturity by transfer without indorsement and who does not acquire the indorsement until after maturity. Under the terms of the Statute ${ }^{249}$ he cannot be a holder in due course, for it is provided that when one secures the indorsement to which he is entitled, the "negotiation takes effect as of the time when the endorsement is actually made" for purposes of determining whether the transferee is a holder in due course.

The most interesting question that has arisen in this regard serves to illuminate the nature of the problem of commercial desirability as herein applicable. This is whether the post-maturity taker, otherwise a holder in due course, is subject to both personal defenses and claims of ownership of the instrument. It is clear that he is subject to personal defenses, both from the policy of encouraging the highest type transaction and from the strict legal logic of the post-maturity-taking factual set-up. The fact that the paper is in circulation after maturity, unpaid by the principal obligor, is thought to suggest that, perhaps, the obligor or some one below him had a defense to liability causing him to refuse to pay at maturity. Thus, there is "constructive notice" (a doctrine abandoned by the Statute) of the equity of defense, from the fact of the instrument's being unpaid and still at large after it should have been paid.

But does this necessarily indicate the possibility that some other person has an adverse claim of ownership to the instrument, where

245. Ibid. Cf. $\$ 45$.

246. § 4. See \$§ 6 (I), II, I2.

247 . $\$ \$ 53,193$.

248. \$ 7 -end.

249. § 49 . 
there is no equity of defense? Professor Chafee has argued ably that it does not, ${ }^{250}$ although the Statute is apparently contrary to this point of view. If the emphasis should be on the constructive notice aspect of the fact of post-maturity circulation, then the post-maturity taker (who is otherwise a holder in due course) should be immune from claims of ownership. If, on the other hand, the emphasis is on the policy of encouraging only the highest type of transaction, then the post-maturity taker should as well be subject to claims of ownership as personal defenses. By that view, taking after maturity brands the transaction as one of the lower level entitled at best only to the procedural advantages.

But Professor Chafee has pointed out ${ }^{251}$ that, after all, there is a policy argument for encouraging the circulation of overdue paper, and that this should be fostered by granting to such takers at least the immunity from claims of ownership, even though, obviously, they should not be immune from personal defenses. After all, if commercial policy is to be the explanation, it must be applied flexibly, and in this vein the Chafee view seems the correct one. We have already seen a certain confusion between the policy of encouraging only the highest type transaction and that of encouraging the simple use of the negotiable instrument form in the relaxing of the rules for an antecedent debt as value and in the proposition that suspicious circumstances, alone, will not defeat a holding in due course. Granting the post-maturity taker an immunity from claims of ownership could be justified similarly as a means of encouraging a transaction of an "in-between" level of commercial desirability by awarding part, but not all, of the substantive advantages. It would thus seem commercially desirable to have the rule be that a post-maturity taker may be a holder in due course subject to the risk of personal defenses to liability.

\section{The Commercial Conduct Terminating the Advantages}

We have been dealing with those operative facts which go to create the various advantages flowing to the two types of holders of negotiable instruments, which are extended in pursuance of the policy of stimulating the greater use of bills and notes and the benefits incidental thereto. At this point we shall treat of those facts which serve to terminate the advantages, assuming them once to have been validly created. Just as the facts serving to create those advantages might create them generally, or only against certain persons, or in favor of certain persons, so do the facts tending to terminate the advantages, i. e., to "discharge" or avoid either the instrument, or the rights and/or liabilities of certain parties, 
serve to terminate them either entirely, or only against certain persons, or in favor of certain persons. ${ }^{252}$

There must be distinguished, however, certain factors which at first might seem to terminate these advantages, yet, in law, do not. One is the maturity of the instrument. The other is its loss or accidental destruction. Neither operates to bring to an end the possibility of either transferring the instrument or proceeding to enforce it by the aid of at least the procedural advantages. While both preclude a holding in due course, as we shall see, yet neither precludes the availability of the procedural advantages. Overdue paper is perfectly capable of being transferred from one ordinary holder to another with no restraint as far as the procedural advantages are concerned. ${ }^{253}$ An instrument which has been destroyed, or lost, may still be sued on as a negotiable instrument, under appropriate local procedure, usually upon the filing of a bond. ${ }^{254}$ The only difficulty is a common-law one, namely, that of proving a lost instrument by secondary evidence. Likewise the right to sue in this fashion may be transferred by assignment.

Then, as showing that "termination" may only be as to the rights of certain but not all holders, ${ }^{255}$ it must be pointed out that the various types of "termination" will not avail if the paper later gets into the hands of a holder in due course. To be sure, certain types, such as the intentional mutilation or entire physical destruction of the instrument, and any event happening after maturity, by nature preclude this possibility. But, to the limited extent to which a subsequent holding in due course is possible, all "termination" is but a matter of personal defense, available against an ordinary holder, but not against a holder in due course. ${ }^{250}$

"Termination of advantages" is of three sorts, the classification of which will provide the topical headings in the ensuing treatment: (A) termination by the completion of the purpose of the instrument; (B) Termination by the intentional act of the holder; and, (C) Termination as a penalty for commercially undesirable conduct.

A. Termination by the Completion of the Purpose of the Instrument

The procedural advantages of an ordinary holder are held out in order to encourage people to shape transactions involving the payment of money into the forms approved by commerce and the law. If and when the actual transaction thus crammed into the mold of the law

252. $\$ 183$ (discharge of one bill in a set is a discharge of all).

253. Contrast the discussion supra, circa notes 248 and 249 , concerning the extent to which maturity should preclude a subsequent acquiring of the substantive advantages. 254. Consider $\$ 160$ (protest of a lost instrument).

255. $\$ 120(\mathrm{I})$.

256. As in \$ II7. 
merchant has come to an end, there is no further policy in favor of extending the procedural advantages to the piece of paper formerly representing it. Thus, any activity which has the effect of completing the purpose of the instrument, viz., by completing the underlying money transaction, will bring to an end the taker's privilege of availing himself of the procedural advantages, and, therefore, of the substantive advantages as well. The policy of stimulating the use of commercial paper needs to be recognized only so long as there exists an underlying common-law transaction to be represented by the approved commercial form.

Thus, payment ${ }^{257}$ "in due course", viz., at or after maturity to the holder ${ }^{258}$ by or on behalf of the principal debtor ${ }^{250}$ or by an accommodated party whatsoever his capacity, ${ }^{260}$ "discharges the instrument" as does the fact of the principal debtor's becoming the holder in his own right at or after maturity. ${ }^{261}$ These are but legalistic ways of expresing the basic concept of the completion of the purpose of the instrument by the termination of the underlying transaction giving rise to it.

On the other hand, the indorser (other than an accommodated one who is really the party ultimately liable in the underlying transaction) who re-acquires the instrument either by intentional purchase or because he is forced to pay off on his secondary liability to subsequent parties does not thereby complete the purpose of the instrument nor terminate the transaction underlying it and so his act does not terminate the advantages. Such a re-acquirer may re-negotiate the instrument or himself choose to pursue the advantages thereof. ${ }^{262}$

The problem of payment of the instrument before maturity by the principal debtor unaccompanied by surrender or destruction of the instrument is a difficult one. If the instrument be surrendered to the maker (but not the drawer where there is a third person payee ${ }^{263}$ ) upon his payment before maturity, he may re-negotiate $i{ }^{264}$ as the purpose of the instrument is not completed until maturity. Thus the procedural advantages are kept alive. On the other hand, payment before maturity without surrender or cancellation raises problems under that obscure section of the Statute which provides that the instrument shall be dis-

257. Consider $\S 32$ (when part paid, instrument may be indorsed as to residue); $\$ 74$ (instrument must be exhibited at demand and surrendered upon payment); $\$ 47$ (negotiable character ceases when discharged by payment).

258. $\$ \$ 37$ (I), 5 I, 88 .

259. $\$$ II9 (I), I2I. Consider also \$I75 (payment for honor discharges subsequent parties).

260. \$\$ II9 (2), I2I (2).

26r. \$ IIg ( 5 ).

262. \$§ 50, I2I.

263. \$ I2I.

264. § 50. 
charged by any act sufficient to discharge a simple contract for the payment of money. ${ }^{265}$

Another example of termination through the completion of the purpose of the instrument is seen in the rule that the holder's procuring of the certification of a check discharges the drawer and the indorsers. ${ }^{28}$ The purpose of a check is to enable the holder to procure money from the bank. If he elects to accept, instead, the bank's obligation to him, whether a cashier's check or their certification on the original check, he terminates the original transaction involving the drawer and indorsers and, by his accepting and the bank's making the certification, uses the same piece of paper for the purpose of creating an entirely new transaction between the bank and himself.

\section{B. Termination by the Intentional Act of the Holder}

Ample legal provision is made for termination of the advantages independently of the underlying transaction, at the option of the holder of the instrument. If the one who is entitled to the advantages wishes to bring to an end his preferred status under the law, the law enables him to do so. He is empowered to terminate them as to the entire instrument, as to the liability of individual obligors thereon, or as to his own rights alone.

Thus the holder's intentional ${ }^{267}$ cancellation either of the entire instrument ${ }^{268}$ or of the signature of any party thereon ${ }^{268}$ will discharge, respectively, the instrument, or the liability of the party, and will thereby terminate the arvantages either entirely or as against the party thus discharged. Further, when a holder strikes out a signature not necessary to his title, ${ }^{270}$ the party whose signature is stricken and subsequent indorsers are similarly discharged. A re-acquiring indorser who pays the instrument and who wishes to negotiate further is permitted to strike his own and subsequent indorsements. ${ }^{271}$ This, of course, would discharge the persons whose signatures were stricken. On the other hand another section ${ }^{272}$ provides for the case of the reacquirer to whom the instrument has been negotiated back, and allows him to reissue it, with the limitation that he cannot enforce it against one to whom he was liable.

The holder is allowed to renounce as to any party at any time, either by a written act, or by the surrender of the instrument to the

265. § II9 (4).

$266 . \S 188$.

267. § 123 .

268. \& II9 (3).

269. \$120 (2).

270 . \$ 48 .

27I. § I2I.

272. § 50 . 
principal party. ${ }^{273}$ Renunciation as to the principal debtor at or after maturity is a discharge of the entire instrument, while renunciation as to the other parties functions to terminate the procedural advantages only as to those. Renunciation is only a personal defense and so will not affect subsequent holders in due course who are unaware of it. The privilege of the holder to strike out indorsements unnecessary to his title, ${ }^{274}$ thereby discharging the parties whose names are stricken and those subsequent thereto, is, in effect, a form of renunciation accomplishing termination of the procedural advantages.

An unfortunate phrase in the Statute ${ }^{275}$ raises the question of whether the restrictive indorsement of an instrument terminates the procedural advantages incident thereto. This provides that an instrument negotiable in origin shall continue negotiable until restrictively indorsed or discharged by payment or otherwise. This would seem to treat a restrictive indorsement as the equivalent of discharge so far as terminating the procedural advantages is concerned. There is no doubt that a restrictive indorsement cuts off negotiability in one sense, in that it precludes a subsequent bona fide holding, at least as against the restriction for all three types of restrictions. In the case of the "pay only" and "agency" kinds of restriction, a subsequent bona fide holding is

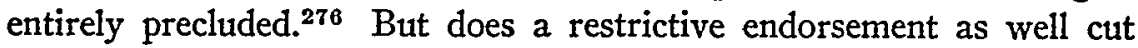
off the other aspects of negotiability, viz., free transfer of the procedural advantages, and the very existence of these advantages? This does not seem to follow, in view of the fact that other sections of the Statute ${ }^{277}$ in providing what shall constitute restrictive indorsements, and what shall be the privileges of holders thereunder, seem to grant to those holding under such an indorsement practically the entire calendar of privileges peculiar to the procedural advantages of an ordinary holder of a negotiable instrument. So even if the restrictive indorsement does purport to terminate the procedural advantages in their own right, it returns them to life under another name.

\section{Termination as a Penalty for Commercially Undesirable Conduct}

The procedural advantages are extended in order to encourage the commercially desirable conduct of dealing in approved types of negotiable instruments. Likewise, there is the policy of cutting off these, and hence the substantive advantages, as a penalty to those who misconduct themselves in connection with such instruments. This penalty is imposed for conduct prejudicial to other parties and running counter to 
the spirit of the law of bills and notes, and its ideas of commercial desirability. Thus presently we shall see three groups of operative facts which will result in the termination of the procedural advantages, even though the purpose of the instrument has not been fulfilled and the party most concerned does not desire such termination. The reason for this is the desire of the law to discourage certain types of commercially undesirable conduct on the part of the holder. These types of conduct are, respectively, the making of an unauthorized change in the physical appearance of the instrument; the release from liability of, extension of time to, or rejection of tender from a prior party; and the failure to protect the interests of secondary parties by performing the commercially desirable conduct of presentment, demand, and notice.

\section{Tampering with the Instrument}

As a penalty for the commercially undesirable conduct of making a material alteration of the instrument, ${ }^{278}$ or of filling in blanks in an unauthorized manner, ${ }^{278}$ or of filling in the wrong date of issue or acceptance which fixes the due date of the instrument, ${ }^{280}$ the instrument is said, in the first situation expressly, and in the others by inference, to be avoided, which means simply that the guilty parties cannot avail themselves of the procedural advantages in enforcing the instrument. This avoiding of the instrument prevails only as to ordinary holders, for later holders in due course may rely on the manner in which the blanks have been filled in, or the date inserted, and may enforce the altered instrument according to its original tenor, though to no further extent.

\section{Release of, Extension of Time to, or Rejection of Tender from a Prior Party}

The second type of termination of the various advantages by commercially undesirable conduct arises when the holder either discharges a prior party, extends privileges to him, or refuses a tender from him, to the possible prejudice of an intermediate party. When this happens, the intermediate party is discharged because of the holder's commercially undesirable conduct. Thus a discharge by the striking of an unnecessary prior signature not only discharges that party but also parties between him and the then holder, ${ }^{281}$ as would any discharge of a - prior party. ${ }^{282}$ The release of the principal debtor, or a binding extension of time on the instrument, also serve to discharge all secondary

278. $\$ 123,124,125$.

279. \& 14.

280 . \$ 13.

281. § 48 .

282. § $120(3)$. 
parties, unless the right of recourse has been reserved against them, or unless the secondary party has assented to the extension of time.283 The doubtful provision discharging the instrument, and hence makers or acceptors, for any act which will discharge a simple contract, ${ }^{284}$ has raised a question as to whether extension of time to the actual principal creditor will as well discharge the surety who occupies the position of maker or acceptor for accommodation. The holder's rejection of a tender by a prior party also serves to discharge subsequent parties. ${ }^{285}$ All of these situations recognize the commercial undesirability of the holder's engaging in conduct prejudicial to certain of the parties and penalize him for so acting by terminating the advantages which, otherwise, he could exercise against them.

\section{Failure to Protect the Interests of Secondary Parties}

The last type of termination of advantages because of commercially undesirable conduct consists in the discharge of drawers of bills ${ }^{286}$ and indorsers of all instruments by the failure of the holder to perform the commercially desirable conduct of prompt presentment of the instrument for acceptance ${ }^{287}$ or payment ${ }^{288}$ and of prompt notice of dishonor ${ }^{289}$ by the drawee, acceptor, or maker, as the case may be. ${ }^{290}$ The policy of thus discharging the secondary parties is, as in all causes for discharge for commercially undesirable conduct, that such conduct may react to the prejudice of the parties who are held to be discharged thereby. As we have seen, among the procedural advantages granted is the automatic inchoate liability of drawers of bills and of indorsers of all instruments. ${ }^{291}$ This peculiar liability is worked out by the law of bills and notes in order to give added attractiveness to the instrument and thereby further to stimulate the circulation of negotiable paper. There is commercial desirability in extending this peculiar type of liability, but commercial desirability in this case has a double edge. $\mathrm{He}$ who wishes to avail himself of this unusual type of liability must himself perform that commercially desirable conduct which is considered fair to those who have this unusual type of liability imposed on them.

An effort must be made to collect the instrument from those contemplated by the law and the parties to be the principal debtors (the makers, drawees, and acceptors) so that the secondary or surety parties

283. \$§ I20 (5), $120(6)$.

284. \$ II9 (4).

285. § I20 (4). Consider also $\$ \$ 70,75,176$.

286. In the case of a check, the drawer is discharged only to the extent of the actual damage suffered, $\S \mathrm{I} 86$.

$287 . \$ \$ 143,144$.

288 . $\$$ 70, I5I, I 86 .

289. \$ 89 .

290. \$II8.

29r. $\$ 84$. Consider also $\$ \S 6 \mathrm{I}, 66$-end. 
(the drawers and indorsers) may be saved from the necessity of having to underwrite the transaction and may be enabled promptly to employ their own perhaps superior devices for seeking reimbursement from these primary or principal parties. Thus there is the requirement that, to charge secondary parties, the holder must make a timely presentment of the instrument for payment (and likewise for acceptance in advance of payment if that be required) ${ }^{292}$ failing which, or failing prompt notice of dishonor if such occurred on presentment, the secondary parties are released from the liability which the law, in pursuance of the procedural advantages, had tentatively imposed. Performance of these steps to fix secondary liability (presentment, demand, and notice; or diligence; or protest, as they are variously called), is thought such commercially desirable conduct that the failure to perform them entails the penalty of losing the added advantage of the liability of the drawer and indorsers.

The Statute has designated that conduct which is so commercially desirable that its absence will cause the discharge of secondary parties. No such requirement is imposed in order that primary parties be bound, as they stand to lose nothing by its failure. ${ }^{293}$ It is only because secondary or surety parties are put in a possibly worse position by the failure of the holder to attempt a prompt collection from the primary party or to notify them promptly of the fruitlessness of such efforts, that secondary parties are thus discharged. As to them, diligence is commercially desirable because it may be the means of saving them harmless. As to primary parties, who have no rights of reimbursement, diligence cannot accomplish any such result and so is not felt to be so commercially desirable as to be necessary as a condition of their liability. ${ }^{294}$

The Statute sets out at great length the details of this matter of performing the commercially desirable conduct of attempting to collect from the principal debtor and of notifying the surety or secondary parties if the effort is fruitless. Presentment of a bill for acceptance in advance of its being presented for payment is only required in those situations where commercial desirability demands it, viz., where the bill explicitly calls for it, where such extra act is necessary to start the running of the period after sight which fixes the ultimate maturity of the instrument, and where the bill orders the unusual conduct of paying elsewhere than at the residence or place of business of the drawee. ${ }^{205}$ On the other hand, if an actually unnecessary presentment for acceptance in advance of the due date is made, the secondary parties are

293. $\$ 70$. Consider also $\$ \S 60,62$.

294. See supra note 284 , regarding the different rule for checks.

295. § I 43 . 
entitled to notice of dishonor at that time, and if it is not given, they are discharged. ${ }^{206}$ Normally, however, presentment for payment, and notice of dishonor are the typical acts the failure of either of which will terminate the procedural advantages of the secondary liability of drawers and indorsers. Provision is made determining by whom ${ }^{297}$ and to whom ${ }^{298}$ presentment must be made and providing in what circumstances notice may or must be given in order to avoid the consequences of discharge of secondary parties. Further statutory detail attempts to work out exactly what constitutes commercially desirable conduct with reference to the time, ${ }^{209}$ the place ${ }^{300}$ and the manner ${ }^{301}$ of making a required presentment or of giving a required notice of dishonor.

The concept of commercial desirability is recognized in the various rules excusing or dispensing with presentment and/or notice in certain events. It is permitted for the parties entitled to these steps to make express waiver thereof as to one or both. ${ }^{302}$ Certain types of impossibility of accomplishing these steps with proper diligence excuse or postpone the necessity of performing them. ${ }^{303}$ In situations wherein the party normally entitled to diligence is, by virtue of his dual function in connection with the instrument, already aware of those things of which presentment and notice would also inform him, the formality of taking these steps is dispensed with. ${ }^{304}$ The commission by the one normally entitled to these acts of the commercially undesirable conduct of stopping payment, ${ }^{305}$ of drawing on a fictitious drawee, ${ }^{306}$ of drawing on or endorsing for one really serving as accommodation party, for the former's own convenience, where the secondary party has no right to expect the drawee or acceptor to honor the order, ${ }^{307}$ also serve to dispense with the right of a party so acting to notice. Thus one who is himself guilty of commercially undesirable conduct, is not allowed to demand the normally commercially desirable conduct from the holder. Further, defective presentment for acceptance is cured by the drawee's refusal to accept on some other ground. ${ }^{308}$ And actual dishonor upon a timely or permitted presentment for acceptance, followed by prompt

296. $\$ ₫ 116,151$.

297. \$\$ 145,72 (I), 90 to 94 , inclusive.

298. \$\$ $72(4), 76$ to 78 , inclusive, $82(2), 94,97$ to Ior, inclusive, 145 .

299. $\$ \$ 71,72(2), 75,85,86,94,102,103,104,107,144$ to 147 , inclusive, $193,194$.

300. $\$ \$ 72(3), 73,76,77,78,87,98,103$, 104, 108. Consider also $\$ \S 6(3), 46$.

301. $\$ \$ 74,95,96,105,106,136$.

302. $\$ \$ 82(3)$, I09, IIO, III.

303. $\$ 76,81,82(2)$, II 2,147, r 48 . Consider also $\$ \$ 82$ (I), Ir3.

304. \$\$ II4 (I), II4 (3), II5 (2).

305. § II 4 (5).

306. §§ I14 (2), I48 (r).

307. $\$ \$ 7,80$, II4 (4), II5 (I), II5 (3). Consider also $\$ \$ 82$ (2), I30.

308. \& I 48 (3). 
notice of such will render unnecessary further presentment for payment and notice of dishonor by non-payment for a bill. ${ }^{309}$ Specific provision is made to determine what conduct does constitute that dishonor which in turn makes notice a necessary item of fixing the liability of secondary parties. $^{310}$ In the case of a foreign bill, viz., one apparently and actually drawn and payable in different jurisdictions, the steps of presentment and notice necessary to fix the liability of secondary parties are required to be performed in the formal manner called protest, that is, before a notary public whose certificate thereabout serves as evidence of the happening of the steps. This formality, which the law demands only in the case of foreign bills but permits in the case of other bills and all notes, is required because it is commercially desirable that an accurate record of the necessary events be preserved. Otherwise it would be difficult for parties at a great distance from each other to procure proper evidence of these facts which are necessary to fix liability. ${ }^{311}$

309. $\S$ II6, I5I.

310. $\$ 883,84, \mathrm{I} 33,136,142,148,149,150,188$.

31 . $\$ \S 118,152$ to 160 , inclusive. 